\title{
Flipping the Introductory American Politics Class: Student Perceptions of the Flipped Classroom
}

Shannon Jenkins, University of Massachusetts, Dartmouth

ABSTRACT Much attention has been centered on the use of emerging technologies in higher education, including flipped classes. However, widespread admiration for and adoption of these innovations seems to be occurring at a much faster pace than the assessment and evaluation of them. Questions about student performance in and perception of flipped classes remain unanswered, so more research is needed. This study examines student perceptions of a partially flipped Introduction to American Politics course. In general, the results indicate that students preferred the partially flipped format, although (1) it is not clear that students would prefer a fully flipped course, and (2) some aspects of the flipped format worked better than others.

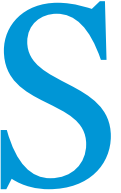

ince two Colorado high school chemistry teachers recorded videos of their lectures, posted them on the Internet, and coined the term "flipping the classroom" in 2007 (Bergmann and Sams 2012), there has been an explosion of interest in this concept, in the mainstream media as well as scholarly conferences and journals. However, discussion of this pedagogical strategy seems to be running well ahead of its assessment. Questions regarding whether students prefer these classrooms, whether they learn more, and whether the style works better in some disciplines than in others currently remain unanswered; the research provides both affirmative and negative evidence.

For political science, understanding student perceptions of and performance in flipped classrooms is critical for determining the utility of this strategy in the discipline. In many universities, introductory political science courses fulfill general-education requirements-that is, they often are large in size and more likely to rely on the traditional lecture. If the flipped-class model does not lead to improved learning and students dislike it, then it may be a delivery mode better suited to other disciplines. However, if flipping the classroom leads to improved learning and students enjoy the experience (or if at least one positive outcome occurs without a negative impact on the other), then it is worth considering how to use this strategy in political science.

This study examines student perceptions of flipped-class sessions in a large, introductory American politics course to determine whether students prefer a partially flipped format to a more standard format. The results indicate that the students'

Shannon Jenkins is associate professor and chair of political science at the University of Massachusetts, Dartmouth. She can be reached at sjenkins@umassd.edu. overall perception of the flip was positive; however, their response was more positive in certain aspects as opposed to others, which reinforces the notion that faculty must think carefully about how to flip their classes.

\section{THE FLIPPED CLASS}

Although there is much discussion about flipping the class, there is little consistency in the definition of the term, causing confusion about what is being examined (Margulieux et al. 2014). Many definitions of flipped learning focus on the use of video lectures outside of class, with class time devoted to in-class activities that help students apply and practice what was learned outside of class (Bergmann and Sams 2012; Carpenter and Pease 2012; EduCause 2012; Hamdan et al. 2013; Morin et al. 2013; Tucker 2012). However, critics point out the problems with this definition: flipped classes relying on lectures delivered via videos are simply replicating a pedagogical model proven to have many limits (Bligh 2000). As a result, other scholars have sought to define the term more broadly to indicate that the key to the flipped model is not the provision of lectures outside of class time but rather the provision of content, via various mechanisms, outside of class time. With content provision moved outside of the class, in-class time is devoted to other activities, such as active learning, critical thinking, and problem solving (CITL 2013). Proponents of this view note that educators have been "flipping" the class for many years (Berrett 2012); it is the explosion of technological resources that has led to increased interest in this strategy. Regardless of how content is provided outside of class, most educators agree that the key to successful flipping is thinking carefully about how content acquisition is integrated with activities that form the core of the in-class experience (Herreid and Schiller 2013; Tucker 2012). 
Most research that examines flipped classes relies on the first definition and generally finds that flipping is beneficial in terms of student-learning outcomes (Berrett 2012; Day and Foley 2006; Papadopoulos and Roman 2010; Warter-Perez and Dong 2012). However, not all research shows consistently positive outcomes; for example, Love et al. (2013) found that students in a flipped algebra class performed better on course exams, although the final-exam results were no different than their peers in a more traditional format. In political science, Roscoe (2012) did not use the term "flipped class" in his study of an upper-level political science course, but he found no significant difference in learning outcomes between students attending a face-to-face version of a course and those who watched lectures online in a blended version. Therefore, with respect to academic outcomes, some studies showed that students do no worse in a flipped class, while other studies found that students perform better. expanded version of an American government textbook. Approximately two class periods were devoted to each chapter in the text, so it seemed critical to ensure that students were reading the text because it was the primary mechanism for full content coverage. Thus, the class was flipped, in that content coverage occurred mostly outside of class via the text readings and online quizzes that were due on the day we began to cover a specific chapter in class. For example, if we started talking about Congress on a Monday, the Congress quiz had to be completed prior to the start of that Monday class. While most of the quiz questions were multiple-choice, the last question was open-ended. Students were asked: "For which concept, issue, or section of Chapter X would you like clarification? Please submit a question related to this topic for in-class review."

Quizzes were due immediately prior to the first class session on any given topic, and I was not prepared to flip every course session.

\section{Student engagement in the flipped-class format is another critical research question, particularly if negative perceptions lead to decreased student engagement with and interest in a subject matter.}

Student engagement in the flipped-class format is another critical research question, particularly if negative perceptions lead to decreased student engagement with and interest in a subject matter. Some research, focusing mainly on science, technology, engineering, and mathematics (i.e., STEM) courses, reports that students prefer the flipped learning experience to the more traditional class experience (Herreid and Schiller 2013; Love et al. 2013). However, other studies suggest that students do not prefer the flipped-class approach, as demonstrated by lower student evaluations of the course (Berrett 2012) and lower student satisfaction (Frederickson, Reed, and Clifford 2005; Stayer 2012). This has led some to argue that perhaps the flipped model is not well suited for introductory classes, where students may not have the skills, interest, and motivation that a flipped class requires (Hamdan et al. 2013).

This may be particularly problematic for political science courses and departments. Lower-level introductory classes tend to be larger and often fulfill general-education requirements. That is, students enroll seeking to check a box, not with a burning interest in or knowledge of politics or political science (Gasim, Stevens, and Zebidi 2012). To the extent that these introductory courses serve as pathways to upper-level political science courses, minors, and majors, students' negative perceptions of the flipped model may be of particular concern for political science departments-and may be a reason to avoid this format. To study this issue, this analysis examines student perceptions of a partially flipped classroom in a large Introduction to American Politics class: Are students turned off or engaged by the flippedclass model?

\section{METHODS: COURSE AND DATA DESCRIPTION}

In the spring of 2013, I taught an Introduction to US Politics course in a large, theater-style classroom to approximately 140 students. Most of the students (97.8\%) enrolled in the class were not political science majors and were taking the class to fulfill a university or college requirement. The content covered in the course was fairly typical, following the standard chapters in an
Therefore, I spent the first 50-minute session for each topic lecturing on two or three key points, with interspersed i>clicker questions and short videos. I referred to these classes as instructorled sessions. However, the second session for every topic was organized around the questions that students submitted for the quiz; these comprised the flipped sessions. Prior to each flipped class, I downloaded the results of the open-ended quiz question and looked for common themes. I also created a word cloud as a visual demonstration of the students' questions. Figure 1 illustrates a sample word cloud on the topic of federalism.

The word clouds helped students see common themes in the questions. For example, two themes emerged for federalism: state versus national power and the types of powers in the Constitution. During the flipped sessions, I began by having students engage in a group task, which typically entailed developing responses to their own questions, since research has shown that peers teaching peers can be highly effective (Whitman 1988). This task was followed by an activity, video, or short discussion of the topic and an i>clicker question to gauge students' understanding of the theme. Finally, I provided a short clarification to address any lingering misconceptions.

Thus, approximately half of the class sessions were flipped. ${ }^{1}$ At the end of the semester, I administered a survey to the students to assess their perceptions of this flipped format. The questions asked them to reflect on their overall feelings about the course, their perceptions of this course as compared to other courses, and whether they felt that different aspects of the flip were beneficial. Their responses were matched to student academic data (i.e., high school GPA and SAT scores and cumulative college credits) and demographic data (i.e., sex, minority status, and age), which allowed me to examine whether their perceptions varied across these characteristics. Overall, 72 of the 140 enrolled students completed the end-of-semester survey. Of the 72 respondents, $17 \mathrm{did}$ not provide a student ID, so they could not be matched to control data. The following descriptive analysis of the results includes all responses, while the multivariate analysis includes only those 
Figure 1

\section{Sample Word Cloud Diagram}

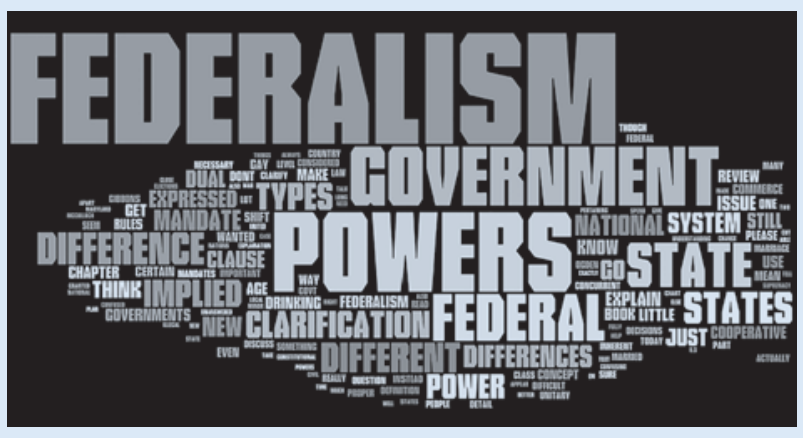

respondents who could be matched. Although the average grades of those students who completed the survey were slightly higher than the overall class average (i.e., 2.35 versus 2.07), both were still in the $\mathrm{C}$ range. students were not so turned off by the format as to prevent them from recommending the class to others.

The survey responses also provided some insight as to why students preferred the flipped-course format. First, they were the least positive about working in groups in class. Only $37.5 \%$ of students strongly agreed or agreed with the statement: "Working with groups in class sessions helped further my understanding of the course materials." Almost 28\% strongly disagreed or disagreed with this statement (see figure 2). This does not necessarily mean that group work is bad; research has demonstrated that positive benefits stem from well-designed group work in class (Pollock, Hamann, and Wilson 2011; Rothgeb 2013). The negative responses may be due more to the nature of this particular classroom. With more than 140 students and a lecture hall without movable seating, it was difficult for students to work comfortably in groups. Moreover, the instructor could not monitor whether each group and all group members were actively working on the assigned task.

Students were more positive about the use of technology in furthering their understanding of course materials; $54.2 \%$

\section{In general, students responded positively to the flipped-class format. For instance, as shown in figure 2, more than half (i.e., 52.2\%) either strongly agreed or agreed with the statement: "I prefer the format of this class to other classes."}

\section{RESULTS}

In general, students responded positively to the flipped-class format. For instance, as shown in figure 2, more than half (i.e., $52.2 \%$ ) either strongly agreed or agreed with the statement: "I prefer the format of this class to other classes." Only slightly more than $10 \%$ (i.e., 10.2\%) strongly disagreed or disagreed with this statement. Students also overwhelmingly indicated that they would recommend this course to others; $86.1 \%$ strongly agreed or agreed with this statement. Of course, these results may not be due necessarily to the class format; the instructor or the subject matter are alternative explanations. However, these results show that

\section{Figure 2}

Survey Responses to Likert Questions

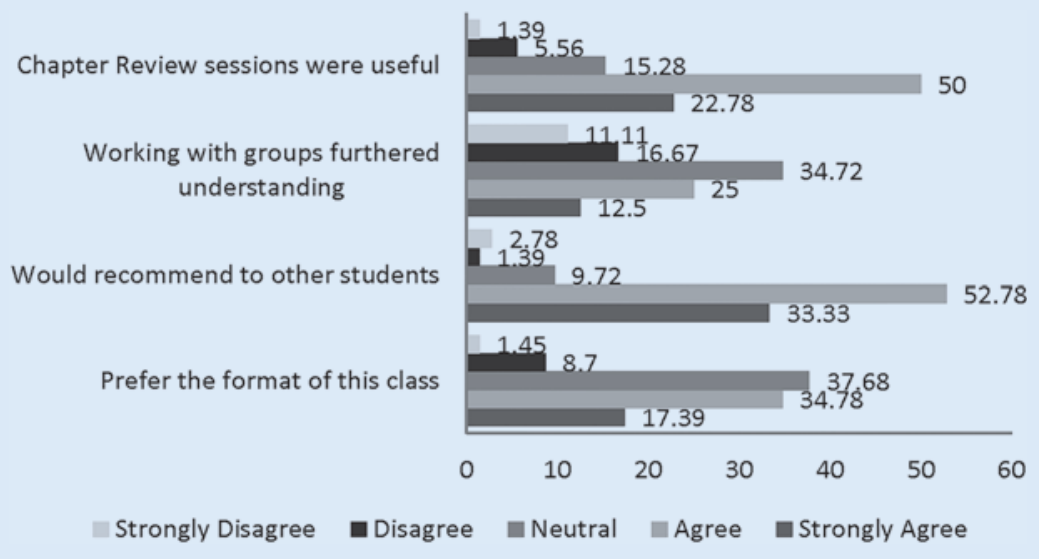

Note: Numbers represent the percentage of students who selected each response option. indicated that the technology (i.e., online quizzes, i>clickers, and short videos referenced in the survey question) provided a better opportunity to master the subject. Few students (i.e., 12.5\%) believed that the technologies detracted from course-content mastery. As noted previously, however, some of these technologies-namely, the i>clickers and the short videos-were used in both the instructor-led and the review sessions, so this result cannot be related exclusively to the flipped nature of the course.

Students were most positive about the course review sessions (see figure 2). More than three quarters of the class (i.e., 77.8\%) strongly agreed or agreed with the statement: "The review sessions for each chapter were useful in helping me understand the materials." Only 5 of the 72 students who responded to this question strongly disagreed or disagreed with the statement.

However, while students believed that the course review sessions were useful, they did not indicate a desire for more of them. First, students were asked about the frequency of the review sessions; the overwhelming majority (i.e., 94.4\%) indicated that a review session every other class was appropriate. Only four students wanted the review sessions to occur more frequently. Additionally, few students indicated that they 
Table 1

Ordered Logistic Regression Models Predicting Student Perceptions of the Flipped Class Format

\begin{tabular}{lccccccc} 
& $\begin{array}{c}\text { Prefer Flipped } \\
\text { Format }\end{array}$ & $\begin{array}{c}\text { Would } \\
\text { Recommend }\end{array}$ & $\begin{array}{c}\text { Work With } \\
\text { Groups Useful }\end{array}$ & $\begin{array}{c}\text { Chapter Review } \\
\text { Useful }\end{array}$ & $\begin{array}{c}\text { Technology } \\
\text { Useful }\end{array}$ & $\begin{array}{c}\text { More Frequent } \\
\text { Flipped Sessions }\end{array}$ & $\begin{array}{c}\text { Prefer Flipped } \\
\text { Sessions }\end{array}$ \\
\hline Female & $-1.100(.693)$ & $-.430(.671)$ & $-.770(.630)$ & $-.265(.655)$ & $.376(.738)$ & $1.411(.982)$ & $-.062(.735)$ \\
\hline Student of Color & $.248(.308)$ & $.278(.360)$ & $.143(.188)$ & $.204(.253)$ & $.256(.403)$ & $-.039(.317)$ & $-.007(217)$ \\
\hline Age & $-.176(.276)$ & $-.008(.270)$ & $-.195(.264)$ & $.185(.271)$ & $-.109(.280)$ & $.172(.413)$ & $.164(.298)$ \\
\hline HS GPA & $.232(.813)$ & $.620(.741)$ & $.366(.732)$ & $.850(.761)$ & $1.166(.838)$ & $-2.126^{\wedge}(1.121)$ & $.206(.833)$ \\
\hline SAT Math + Verbal & $-.003(.003)$ & $-.002(.003)$ & $-.004(.003)$ & $.000(.002)$ & $-.002(.003)$ & $.004(.004)$ & $-.000(.003)$ \\
\hline Cumulative Credits & $-.023(.017)$ & $-.023(.018)$ & $-.001(.015)$ & $-.030^{\wedge}(.107)$ & $-.016(.016)$ & $-.026(.024)$ & $-.019(.017)$ \\
\hline N & 44 & 46 & 46 & 46 & 45 & 46 & 46 \\
\hline Pseudo R2 & .108 & .062 & .035 & .068 & .093 & .103 & \\
\hline
\end{tabular}

Note: $\wedge=p<.10$. For the first four columns, a Likert response scale was used; higher responses equal stronger agreement. For the technology question, a higher response equals a more positive evaluation of the technology. A lower response for the review frequency question means the student felt the review sessions occurred too frequently. For the last column, responses were coded so the lowest score indicates a preference for instructor led sessions, while the highest score equals a preference for sessions designed around student questions.

preferred course review sessions designed and arranged around student questions to those designed by the instructor. Most students (i.e., 59.7\%) preferred a mix of sessions, while only 8.3\% expressed a preference for sessions focused on student questions. In fact, more students (i.e., 31.9\%) preferred sessions designed by the instructor. Thus, students' perceptions of the flipped-class format in this course were generally positive, which apparently stems from the technology used in class and the course review sessions designed around student questions. Students were less positive about the group work in class.

Finally, the perceptions seemed to be shared across all types of students. Ordered logistic regression models were run to determine whether some students responded to the format more positively than others, as shown in table 1 . Students with more credits were slightly less likely to indicate that the flipped review sessions were helpful, while students with higher entering GPAs believed that they were too frequent. It is not altogether surprising that more advanced and better-performing students had fewer positive responses to the flipped review sessions as they may believe that they needed them less than others. Otherwise, there were no significant differences in responses across the variety of control variables. Furthermore, these variables do not do a very good job in explaining variation in responses to the questions. However, which other variables might work better remains an open question. Nevertheless, these results reveal that student perceptions of the flipped-class format were not driven by differences in the types of students enrolled in the course.

\section{CONCLUSION}

Although there has been much excitement about flipping classes, there also has been confusion about what it means exactly and whether students like and perform better in this class format. Using a broad definition of flipping the class and focusing on the provision of content outside of class while using in-class time for active learning, this analysis examines whether changing to a flipped-class format had a positive or negative effect on student perceptions. Overall, the results demonstrate that students responded positively. However, their responses indicate that they also preferred having mixed class sessions-that is, some instructor-led sessions and some designed around student questions-to having all flipped-class sessions. Furthermore, students were less positively inclined toward the group work that came in the flipped-class sessions, which reinforces a critical point. It is not enough to simply upload some lectures to YouTube and call it a flip. Instructors must think carefully about how to deliver content outside of the class, how to ensure that students understand that content, and how to integrate it with in-class activities.

Finally, although some educators question whether the flippedclass format works well in an introductory-level course, this study shows that it can. In political science, introductory courses often are larger, with students of varying levels of interest and preparedness. Flipping the class can ensure that all students begin to study a given topic with at least some degree of background knowledge, become engaged in active learning about the subject matter, and leave the classroom with a better understanding of the course material. To the extent that introductory-level classes also serve as gateways to upper-level classes, minors, and even majors, flipping the classroom may be a good strategy for engaging more students in the study of political science.

\section{NOTE}

1. The total is not quite $50 \%$ due to in-class exams.

\section{REFERENCES}

Bergmann, Jonathan, and Aaron Sams. 2012. Flip Your Classroom: Reach Every Student in Every Class Every Day. Eugene, OR: International Society for Technology in Education.

Berrett, Dan. 2012. "How 'Flipping the Classroom' Can Improve the Traditional Lecture." The Chronicle of Higher Education. Available at http://chronicle.com/ article/How-Flipping-the-Classroom/130857 (accessed December 6, 2013).

Bligh, Donald A. 200o. What's the Use of Lectures? San Francisco: Jossey-Bass.

Carpenter, Jeffrey P., and Jennifer S. Pease. 2012. "Sharing the Learning." Phi Delta Kappan 94 (2): 36-41.

Center for Innovative Teaching and Learning (CITL). 2011. "Flipping' the Class." Available at http://citl.indiana.edu/resources/teaching-resources1/flipping-class. php (accessed December 6, 2013).

Day, Jason A., and James D. Foley. 2006. "Evaluating a Web Lecture Intervention in a Human-Computer Interaction Course." Institute of Electrical and Electronics Engineers Transactions on Education 49 (4): 420-31. 
EduCause. 2012. "7 Things You Should Know About...Flipped Classrooms." Available at http://net.educause.edu/ir/library/pdf/ELI7081.pdf (accessed December 6, 2013).

Frederickson, Noah, Phil Reed, and Viv Clifford. 2005. "Evaluating Web-Based Learning Versus Lecture-Based Teaching: Quantitative and Qualitative Perspectives." Higher Education 50 (4): 645-64.

Gasim, Gamal, Tara Stevens, and Amira Zebidi. 2012. "Analytical Study of SelfMotivations among a Southwestern Public University Nonpolitical Science Major Students in Required Political Science Courses." Journal of Political Science Education 8 (2): 107-19.

Hamdan, Noora, Patrick McKnight, Katherine McKnight, and Kari M. Afrstrom. 2013. A Review of Flipped Learning. Available at www.flippedlearning.org/review (accessed December 6, 2013).

Herreid, Clyde Freeman, and Nancy A. Schiller. 2013. "Case Studies and the Flipped Classroom." Journal of College Science Teaching 42 (5): 62-6.

Love, Betty, Angie Hodge, Neal Grandgenett, and Andrew W. Swift. 2013. "Student Learning and Perceptions in a Flipped Linear Algebra Course." International Journal of Mathematical Education in Science and Technology. 45 (3): 317-324.

Margulieux, Lauren E., Keith R. Bujak, W. Michael McCracken, and David Majerich. 2014. "Hybrid, Blended, Flipped, and Inverted: Defining Terms in a TwoDimensional Taxonomy." Presented at the Hawaii International Conference on Education, January. Honolulu, HI.

Morin, Brooke, Krista M. Kecskemety, Kathleen A. Harper, and Paul A. Clingan. 2013. "The Inverted Classroom in a First-Year Engineering Course." Paper presented at the American Society for Engineering Education, June 23-26. Atlanta, GA

Papadopoulos, Christopher, and Aidsa I. Santiago Roman. 2010. "Implementing an Inverted Classroom Model in Engineering Statistics: Initial Results." Presented at the 4oth Annual ASEE/IEEE Frontiers in Education Conference, October. Washington, DC.

Pollock, Phillip H., Kerstin Hamann, and Bruce M. Wilson. 2011. "Learning Through Discussions: Comparing the Benefits of Small-Group and Large-Class Settings." Journal of Political Science Education 7 (1): 48-64.

Roscoe, Douglas D. 2012. "Comparing Student Outcomes in Blended and Face-to-Face Courses." Journal of Political Science Education 8 (1): 1-19.

Rothgeb, John M. 2013. “The Efficacy of Learning Teams: A Comparative Analysis.” Journal of Political Science Education 9 (3): 336-44.

Stayer, Jeremy F. 2012. "How Learning in an Inverted Classroom Influences Cooperation, Innovation, and Task Orientation." Learning Environment Research 15 (2): 171-93.

Tucker, Bill. 2012. "The Flipped Classroom: Online Instruction at Home Frees Class Time for Learning." Education Next (winter): 82-3.

Warter-Perez, Nancy, and Jianyu Dong. 2012. "Flipping the Classroom: How to Embed Inquiry and Design Projects into a Digital Engineering Lecture." Presented at the 2012 Society for Engineering Education Pacific Southwest Annual Conference. San Luis Obispo, CA.

Whitman, Neal A. 1988. Peer Teaching: To Teach Is to Learn Twice. San Francisco: Jossey-Bass. 